\title{
Gender and Development Cooperation: Scaling up Work with Men and Boys ${ }^{1}$
}

\section{Paul Dover}

\begin{abstract}
Work with men and boys for gender equality and women and girls' empowerment has reached a stage of critical mass within development cooperation. Efforts are now needed to scale up interventions and to embed them in policy and practice. The article is written from the perspective of development bureaucracy and examines the background and the current contexts for work with men and boys and suggests main entry points for future developments.
\end{abstract}

\section{Background}

There is currently a lot of interest in working with men and boys on gender equality issues. It is coupled with perceptions on the need for male engagement and support to achieve gender equality, as well as the imperative to change destructive aspects of masculinity that impact so negatively on our societies. Furthermore, there is now a large body of evidence from surveys, applied research and pilot projects on men and masculinities, as well as an increasing number of men's gender justice organisations in place to take the work forward.

Thus there exists a critical mass of interest, evidence and capacity for work with men and boys. At the same time, a number of feminists and women's rights activists are critically sceptical of working with men and boys for female empowerment. Women's organisations also fear that funding to men's gender equality organisations will reduce the dwindling civil society organisation (CSO) development cooperation support to women's rights organisations even further.

What does all this mean for a development cooperation organisation such as Sida? Sweden prides itself as a leading nation on gender equality and it is seen as an area of distinct comparative advantage in the country's development cooperation. According to OECD-DAC's 2013 report Aid in Support of Gender Equality and Women's Empowerment - Donor Charts, ${ }^{2}$ approximately 83 per cent of Sweden's aid in 2011 had gender equality as a significant or principal objective. This article first looks briefly at the historical background to working with men and boys for gender equality. Secondly it sketches out the current contexts within development cooperation bureaucracy, followed by the international arena and agendas. The article suggests the easiest entry points and venues for moving forward in scaling up the work with men and boys for gender equality through structural integration.

\section{From women in development (WID) to gender and development (GAD)}

Sweden's international policy on gender equality (GOS 2010) states that 'Gender equality is achieved when women and men, and girls and boys, have equal rights, life prospects and opportunities, and the power to shape their own lives and contribute to society' (p.7). Given women and girls' disadvantaged position and status, the main efforts in Sweden's development cooperation focus, naturally, on improving their situation. Sweden's policy outlines four broad work areas: women's political participation and representation, women's economic empowerment (WEE), sexual and reproductive health and rights (SRHR), and women's security including combating gender-based violence (GBV) and trafficking. Men and boys are referred to in the 
policy in relation to achieving goals for women and girls, such as within SRHR and preventing GBV.

Development cooperation work with men has antecedents as far back as the 1970s. For example, the International Planned Parenthood Federation (IPPF) had pilot outreach to men within Maternal and Child Health programmes. It was not, though, until the conceptual switch from women in development (WID) to gender and development (GAD) that a focus on men and boys became more apparent. Three factors can be seen in relation to the switch to GAD. Firstly, the GAD focus on power and household analysis laid bare aspects such as unpaid work burdens, women's triple roles (care work, community work and income activities), and female lack of control of resources. Secondly, mainstreaming became the main method to ensure gender considerations were addressed within development cooperation. This again involved examining how interventions affected beneficiaries - necessitating issues such as power analysis and examination of constraints to female participation. Thirdly, there was the understanding of the inter-relational and contextual nature of gender and how it conjoins with other identities and social hierarchies such as age, ethnicity, wealth, class and religion.

What is often missing in development cooperation approaches to gender, including Sweden's, is the inter-relational lens of gender analysis. Moreover, the gender analysis is often confined to women and girls; it generally ignores men and boys' situation. To support efforts for women and girls' empowerment, one needs to understand the social contexts in which efforts are being made. For example, support to developing women's entrepreneurship is often hindered by women's care-work tasks, as well as their lack of economic decision-making power at household level.

Moreover, another known obstacle is male resistance to women's empowerment in situations of poverty and economic stress, in which men feel ashamed because of their inability to live up to 'household breadwinner' expectations. Thus whilst work with men and boys within support to women's economic empowerment can be triggered by males being a problem, response interventions can work from a transformative perspective. The so-called crisis of masculinity can be used to develop new male roles in which more equitable and caring forms of masculinity can emerge.
Whilst health organisations and some women's rights organisations have focused work on men and boys, a major factor in the current 'critical mass' is the rise of men's organisations for gender equality ${ }^{3}$ and their global and regional organisation. The MenEngage Global Network is the main international organisation with over 400 NGO members of the alliance, as well as a number of UN $\mathrm{UN}^{4}$ organisations. These 'men's' organisations focus broadly on gender equality and women's rights perspectives, but their development cooperation funding tends to be more mundanely focused on measurable interventions, such as male involvement in SRHR and prevention of GBV.

So why does Sweden fund men's organisations for gender equality and why cannot men become involved in supporting women's rights organisations instead? The organisations working with men have emerged in part from the reflective and transformative approaches developed by men supportive of the feminist movements in the 1970s and 1980s. Part of this process is the need for 'safe spaces' for men and boys to discuss and understand patriarchal privilege, women's subordination and to develop personal responses. Men have also not always been welcome in women's rights venues and there is an amount of scepticism among some feminists. Given concepts, such as the 'patriarchal dividend' - that all men benefit in some way from gender inequality, plus a tendency for male equivocal attitudes and sometimes downright hostility to female empowerment, feminist wariness is not surprising. Moreover, there are various 'men's rights' groups with antithetical agendas. There are some NGO voices raised that work with men and boys is an agenda pushed through by the donors and which is diverting support from women and girls' needs and rights. Funding to CSOs has been dwindling generally, but it is doubtful if support to men and boys is actually making a major dent in financing for women's organisations. Sweden's direct support to gender equality in 2012 was US\$364 million (according to the OECD-DAC ${ }^{5}$ policy codes). A rough calculation is that US\$2.8 million of this funding was directly targeted to men and boys.

Donors are funding men's organisations because of the perceived need to involve men and boys in gender equality work, particularly on issues such 
as SRHR/HIV and GBV. Work with men and boys is not an area on which women's organisations, with a few exceptions, are focusing. There do, though, seem to be increasing alliances between men's gender justice and women's rights organisations at local and national levels, if not so much at the international level. A further trend is the increasing recruitment of women to men's organisations, including to senior management posts. The multilaterals are also increasing focus on work with men and boys, albeit generally within pilot projects. Men and boys' perspectives from the higher ground of the 'patriarchal dividend' are obviously not the same as subordinated women and girls. Hopefully the developments highlighted will lead to a situation in which work with men and boys is firmly situated as complementary support to the broader work of women's rights movements on gender equality in the near future. Funding separate gender equality initiatives for women and men is not optimal in the long run.

As noted above, factors leading to the current critical mass for work with men and boys include a solid body of cross-cultural research. Two linked initiatives stand out in their international uses and thus ability to make cross-comparisons: the Gender Equitable Men (GEM) Scale and the International Men and Gender Equality Survey (IMAGES). The former was developed by the men's organisation, Promundo, together with the Population Council's Horizon programme. It measures baselines and intervention outcomes in relation to a gender equitable attitudes score. The IMAGES survey tool was initially developed by Promundo and the International Center for Research on Women (ICRW). It is a quantitative household survey measuring men's and women's perceptions and behaviours on themes related to gender equality and has now been carried out in 11 countries $^{6}$ and in all regions. A version specifically for GBV has also been used in a regional survey in East and South Asia by the joint UN programme Partners for Prevention (P4P) towards developing evidence-based GBV prevention communication tools.

The GEM scale and IMAGES surveys are examples of how the work with men, boys and gender equality is moving through applied research to measurable interventions. Two challenges emerge from this work; the pilot nature of interventions and measuring change.
Funding tends to be for interesting pilot interventions that show good potential, but are never integrated into policy. If we are to make transformative changes then the work needs to be scaled up. A critique of work on and with men and boys has been that it focuses too much on individual behavioural change and not enough on dealing with structural changes for women and girls' empowerment. There is a certain truth in this observation, and structural work with men and boys is discussed later in this article. Though, of course, individual change and structural facilitation necessarily go hand-in-hand.

A major output has been in the development of methodologies and techniques to address gender inequalities, GBV and male involvement in SRHR both at community level and with groups of men or boys. In terms of measurable outcomes, interventions are increasingly showing short-term positive results, particularly as organisations use baselines and more stringent measurement methodology, such as control groups. Nonetheless, the second challenge is that the theory of change is mostly based on selfreported attitudes and, to a lesser degree, on self-reported behaviours. Without some form of measurement triangulation, for example, proxy indicators, this allows for response bias.

Furthermore, there are few examples of longitudinal measurements of interventions to show sustained change (Ricardo et al. 2011: 7). Thus men's organisations, among other things, need to improve longitudinal mapping of attitude change and to a greater degree link it to measurements of behavioural changes other than self-reporting.

\section{The current contexts}

What are the current contexts within which development bureaucracy finds itself and what are future funding scenarios for gender equality? Development cooperation is currently in a state of flux and change. After 50 years of various developmental approaches, there is a certain fatigue and much debate around what development funding has - and can - achieve. Responses that appear quite general among donors are reducing their own administrative costs and delimiting country and thematic focus. Methods to reduce administrative costs include re-organisation and cutting staff, plus targeting support to large organisations, for example multilaterals and international NGOs that can 
absorb large volumes of funding. There is a focus on funding to lower income countries, in particular in sub-Saharan Africa, post-conflict countries and for humanitarian crises. Within their increasingly diverse approaches, many donors have retained, at least on the policy level, a strong focus on gender equality. Terminology often used is 'women and girls', plus an undifferentiated 'youth' or 'young people'. This is definitely the case for Sweden. The catch-all category 'youth' is rather unfortunate, as it obscures gender differences and needs, as well as huge age differentials.

A major current emphasis among the traditional donors such as Sweden, is on achieving results and developing systematic approaches to measuring and following them up. A results focus tends to be interpreted in quantitative terms. This means that the long-term perspectives of gender transformative goals may need to be strategically nested within shorter-term quantitative objectives. Sweden is developing results strategies as a new form for cooperation. They focus on result areas rather than sectors per $s e$. This means that a results area can use various actors and means, including CSOs or private sector development, to achieve its outcomes. The result strategies approved so far have a strong focus on women and girls, especially from a gender mainstreaming perspective.

One can perceive three main donor trends that have affected NGOs and community-based organisations (CBOs) working with gender equality in recent years. Firstly, the donor concentration on developing sector and budget support in relation to the Paris Agenda has somewhat reduced focus on CSO support. Secondly, at the same time, strengthening local and regional CSO capacity for accountability and advocacy activity is seen as a main task within democracy and good governance efforts. Thirdly, as mentioned above, to reduce administration costs, donors are increasingly supporting large sub-granting bodies or creating umbrella groups though which to channel funds. A further feature is the emergence of so-called innovative financing mechanisms, such as challenge funds for which the administration may be delegated.

Nonetheless, the results agenda does open up opportunities for CSO participation. Moreover, partner governments are becoming less reliant on donor funding and this can lead to an increased focus of support to CSOs, particularly from an accountability and advocacy perspective. CSOs can also play an advisory and supportive role in the development of private sector initiatives.

\section{The international arena}

Turning to the international arena, what are the contexts and focus areas shaping future developments around gender equality? How can a focus on men and boys contribute? A major new actor establishing itself within the multilateral system is the organisation UN Women. The main roles for the organisation are: support to member states, coordinating and following up UN efforts on gender equality, as well as organising and following up the Commission on the Status of Women (CSW). UN Women is taking a strong role on leading efforts against GBV, including a strong focus on primary prevention. ${ }^{7}$ The priority theme of CSW's 57th session of 2013 was on the elimination of violence against women and girls, and this has given a major international boost to increasing efforts against GBV. A major challenge to primary prevention work is measuring levels of GBV and responses to interventions. This is an area in which men's organisations and particularly background work, such as the IMAGES studies can contribute. Primary prevention of GBV obviously entails work focused on men and boys.

Two main tasks on the international agenda are wrapping up the MDG efforts and an international agreement on what is to replace them. Consensus has consolidated around the creation of new global sustainable development goals (SDGs). The SDGs should address all three dimensions of sustainable development, social, economic and environmental. A 30-member Open Working Group (OWG) of the General Assembly is tasked with preparing a proposal on the SDGs. The MDGs are not strong on integrating gender and ignore the structurally embedded issues that underpin gender inequalities. There are, though, some sexdisaggregated indicators. MDG 3 is the only goal towards gender equality and has limited areas of focus; education ratios by sex, women's share of non-agricultural wage employment and proportion of seats held by women in national parliaments. Strong advocacy work is being conducted for both a standalone SDG on gender equality and its integration into the other goals. In addition to the UN processes, the UN Secretary General appointed a High Level Panel 
of Eminent Persons, which has made its recommendations on SDGs, including suggestions for new goals. Their report makes a case for gender equality as a standalone goal, as well as gender indicators to be included in the other goals (UN 2013). The High Level Panel's conclusions are supported by an OECD article (OECD 2013) and UN Women has also published a document (UN Women 2013) supporting a 'transformative' standalone gender equality SDG, accompanied by indicators, as well as integration of gender equality into the other goals. MenEngage has also developed a call of action on the post-2015 agenda (MenEngage et al. 2013) based on the High Level Panel's goals.

A further strand for the SDGs is the International Conference on Population and Development (ICPD) Beyond 2014 Review. Consultative processes are ongoing and a High Level Task Force has given policy recommendations (HLTF for ICPD 2013). These include universal access to SRHR information, education and services, including comprehensive sexuality education for young people, and eliminating violence against women and girls. The ICPD review culminates in an UNGASS session in 2014.

Gender equality work with men and boys does not figure largely in any of these documents. Within a number of the emerging suggested areas, the integration of men and boys could make an important contribution to achieving results. The main areas are, naturally, GBV, SRHR, WEE and women's representation and decision-making power. Moreover, there is the overarching 'results' agenda with its objectives to improve evidence, data-gathering, and harmonise indicators and statistics in which data on men and boys need to be embedded.

Within work on GBV there is the increasing attention to primary prevention. Best practices for support to survivors of violence are somewhat well-established, though they often need adaption to low-income and resource-poor settings including post-conflict and humanitarian contexts. Primary prevention of violence, both by intimate partners and non-partners, is an area under research and the development of evidencebased interventions. The issues are, of course, not limited to development cooperation or lowincome settings. Rather, development cooperation is contributing to the wider arena of reducing men and boys' violence against women and girls. A main challenge is developing responses in post-conflict situations.

SRHR remains firmly in focus among some donors, but it is a controversial area. It faces organised challenges from religious fundamentalists and social conservatism especially in relation to abortion and young people's access to information and services. Funding to HIV is dwindling after a long period in the spotlight and it is being encapsulated within a wider SRHR agenda. Fertility regulation has also returned to international attention. The terminology used is mostly the traditional 'family planning' in relation to 'women's unmet needs for contraception'. The new fertility regulation focus is partly in regard to population dynamics effects on economic growth (i.e. youth employment issues), the environment and climate change. Women and girls' needs and rights in relation to contraception are emphasised, but so far there is little focus on male responsibilities and men as fathers.

The focus on WEE is related to wider efforts on creating inclusive GDP growth. In particular is the concern with the high levels of youth unemployment. Entrepreneurship schemes, within markets for the poor (M4P) approaches, and, to a lesser extent, private-public partnerships are ongoing responses. In relation to employment are also considerations on education sector support. In particular is an emphasis on skills development, given both a lack of needed skills and that purely academic qualifications are no guarantee of a job in many low and middleincome countries. As exemplified above, there is a need to involve men in WEE efforts. This relates also to women and girls' decision-making; a broad area covering household issues, SRHR, decision-making in the private and public sectors, political representation and voice.

Lastly, turning to the results agenda this presents an opportunity to integrate data on men and boys in relation to gender equality. A main task ahead is to ensure increased sex and age disaggregation in the formulation of indicators and statistics. Upcoming areas will be measuring women's empowerment, as well as developing standard indicators for prevalence statistics on GBV and measuring results of the interventions against violence. 


\section{Scaling up}

As noted above, work with men and boys tends to be at pilot level and good results are generally not integrated into policy and scaled up.

Development cooperation funding can improve this situation, in particular by integrating a perspective on men and boys within gender mainstreaming in social sector support. Obvious entry points for sector integration of work with men are boys are education, health, WEE and social protection.

Gender mainstreaming was instituted in the recognition that standalone efforts for women and girls were not enough to address their needs. It has been applied most successfully within health and education sector work and to a degree within agricultural and rural livelihoods support. Funding for work with men and boys has generally not been part of mainstreaming efforts. There is increasing evidence of successful results, but scaling up into structural normative approaches, for example in health and education, seldom takes off. The implementation and advocacy work on men, boys and gender equality is mostly driven by CSOs that struggle to receive core funding, often relying on project funding to survive. UN organisations are incorporating men and boys into their gender work to a greater extent, but they are still generally pilot-orientated interventions.

If work with men and boys for gender equality is to be scaled up from the pilot stage, it needs to be gender mainstreamed within social sector work, as well as supported by an array of external entry points, such as media, workplace and community inputs. Structural approaches necessitate a thematic focus area for the expected results, in which the overall goals of gender equality can be embedded. For example, reducing HIV transmission and sexually transmitted infection (STI), or encouraging fathers' participation in maternal health and the parenting of young children, or preventing gender-based violence within education sector approaches. NGOs working in the area are well aware of the need to scale up responses, but report that a major challenge is to get men and boys for gender equality on ministerial policy agendas. A further obstacle is that even if the policy arena is secured, there is often a lack of resources and capacity for implementation. Working from the bottom up and integrating work with men and boys in ongoing social service delivery has been the pilot method, but the question remains: how does one best scale out and scale up?

Sweden has good examples on social welfare reform and health-sector structural facilitation of fathers' involvement in maternal health and childcare. Fathers are expected to attend some antenatal classes, are generally present at the birth and have ten days' paid work-leave rights to support their partner during the immediate postnatal period. There are also 60 days' 'use it or lose it' of parental leave allowance that the father must take. Men's use of parental leave has increased from 5 per cent in 1980 to 24 per cent in 2011 (SCB 2012: 43) of the total allowance for a couple. Naturally, the situation in many lowand middle-income countries with high levels of informal employment and resource-poor public health facilities is quite different. Nonetheless, there are entry points to integrate men that can be utilised, for example, in Mother Ghild Health programmes and in the roll-out of social protection schemes.

\section{Trends, countertrends and the road ahead}

The need to work with men and boys is because of widespread gender inequities based on male privilege and its concomitant discrimination and violence against women and girls. Not all men, or all women, welcome the message. Backlash reactions to women's and girl's advancement can be found among individual men, as well as formally organised within religious fundamentalist, social or cultural conservative movements and politics, including the emergence of 'men's rights' groups. It is perhaps easier for men and boys living in economically secure situations to accept women's empowerment, than for males living in poverty and insecurity. Nonetheless, many poor men and boys exhibit gender equitable attitudes and are not violent. A further sticking point is the ambivalent or sceptical attitudes on work with men and boys among a fair number of feminists and women's rights activists. They may also perceive the rapid growth and influence of men's organisations with some disquiet, particularly in relation to the funding difficulties that many CSOs experience in the current development cooperation climate.

This article started out by stating that there is currently a critical mass of interest, evidence and 
organisational competence to take the agenda with men and boys for gender equality forward. If the work with men and boys is to progress beyond the pilot stage there is both a need to improve measurements of results and to structurally integrate efforts in sector mainstreaming. It is within structural approaches to scaling up that development cooperation, with its sector support and strengthened results focus, can be most effective in mainstreaming men and boys into work towards gender equality. There is evidence from pilots within health, education and WEE of positive results from integrating a genderequality approach that includes men and boys. That said, continuing to build up an evidence base is important. Main 'low-hanging fruit' for integrating men and boys into gender equality efforts are the GBV and SRHR agendas, plus women's decision-making and representation. There are also economic and social welfare structural changes that enable men to take part in care work and active fatherhood.

Furthermore, in relation to development cooperation results agenda, there is an ongoing focus on developing gender indicators linked to national statistics compilation. Main efforts need to be on increasing sex and age disaggregated data. Including men and boys in measuring efforts for gender equality are particularly

\section{Notes}

1 The following is an individual assessment and does not represent official viewpoints from the Swedish International Development Cooperation Agency (Sida).

2 OECD-DAC Secretariat (2013) Aid in Support of Gender Equality and Women's Empowerment Donor Charts: Statistics based on DAC Members' Reporting on the Gender Equality Policy Marker, 2010-2011 Creditor Reporting System Database, Paris: OECD.

3 Men for gender equality organisations should not be confused with a small backlash movement for 'men's rights'. important in the formulation of SDGs and especially in relation to a possible standalone goal for gender equality.

Whilst structural integration is the way forward, the CSO gender equality work with men and boys will continue to be an important resource. The organisations develop research and knowledge, process it into policy development tools, initiate media coverage and public awareness, as well as pilot evidence-based projects and programmes. Not least, they are important in the advocacy needed at all levels. Gender inequalities are based in, and buttressed by, underlying social and economic norms, attitudes and institutions. Creating cultural and institutional change requires multiple inputs and entry points, which CSOs are well situated to provide. More collaboration between men's gender justice organisations and women's rights organisations are needed in these efforts.

Funding separate gender initiatives for women and men is not optimal in the long run.

To conclude, gender equality is achieved, as stated in Sweden's policy when 'women and men, and girls and boys have equal rights, life prospects and opportunities, and the power to shape their own lives.' Work with men and boys needs to be an integral part of efforts towards these goals.

4 UNDP, UNICEF, UNFPA and UN Women.

5 The OECD-DAC code for gender equality is used to rate all contributions as principle objective (i.e. direct targeted support), significant objective (mainstreamed) or not applicable. The code does not indicate whether the target group or beneficiaries are women, girls, men or boys.

6 Bosnia, Brazil, Chile, Croatia, the Democratic Republic of Congo (DRC), India, Malawi, Mali, Mexico, Rwanda and South Africa.

7 That is to say, proactive, rather than reactive measures against GBV. 


\section{References}

GOS (2010) On Equal Footing: Policy for Gender Equality and The Rights and Role of Women in Sweden's International Development Cooperation 2010-2015, Stockholm: Government Offices Sweden

HLTF for ICPD (2013) Policy Recommendations for the ICPD Beyond 2014: Sexual and Reproductive Health and Rights for All, New York: High Level Task Force for ICPD

MenEngage Alliance; Sonke Gender Justice Network and Promundo (2013) Call for Action: Post-2015 Agenda, Washington DC: MenEngage

OECD (2013) Gender Equality and Women's Rights in the Post-2015 Agenda: A Foundation for Sustainable Development, OECD Post-2015 Element 3, Paper 1, Paris: Organisation for Economic Co-operation and Development
Ricardo, C.; Eads M. and Barker G. (2011) Engaging Boys and Young Men in the Prevention of Sexual Violence: A Systematic and Global Review of Evaluated Interventions, Sexual Violence Research Initiative, Washington DC: Promundo

SCB (2012) Statistics Sweden Women and Men in Sweden 2012, Örebro: Statistiska centralbryån [Statistics Sweden]

UN Women (2013) A Transformative Stand-Alone Goal on Achieving Gender Equality, Women's Rights and Women's Empowerment: Imperatives and Key Components, New York: United Nations

UN (2013) Report of the High Level Panel of Eminent Persons on the Post-2015 Development Agenda - A New Global Partnership: Eradicate Poverty and Transform Economies through Sustainable Development, New York: United Nations 